\title{
Inhibition of transforming growth factor $\beta$ decreases pancreatic fibrosis and protects the pancreas against chronic injury in mice
}

\author{
Yoshikuni Nagashio $^{1}$, Hikaru Ueno ${ }^{2}$, Michio Imamura ${ }^{2}$, Hiroshi Asaumi ${ }^{1}$, Shiro Watanabe ${ }^{1}$, \\ Taizo Yamaguchi ${ }^{1}$, Masashi Taguchi ${ }^{1}$, Mitsuo Tashiro ${ }^{1}$ and Makoto Otsuki ${ }^{1}$ \\ ${ }^{1}$ Third Department of Internal Medicine and ${ }^{2}$ Department of Biochemistry and Molecular Pathophysiology, \\ University of Occupational and Environmental Health, Japan, School of Medicine, Kitakyushu, Japan
}

\begin{abstract}
Transforming growth factor- $\beta$ (TGF- $\beta$ ) is an important cytokine in the fibrogenesis in many organs, including the pancreas. Using an adenoviral vector expressing the entire extracellular domain of type II human TGF- $\beta$ receptor (AdT $\beta$-ExR), we investigated whether inhibition of TGF- $\beta$ action is effective against persistent pancreatic fibrosis, and whether it exerts a beneficial effect on the pancreas in the process of chronic injury. To induce chronic pancreatic injury and pancreatic fibrosis, mice were subjected to three episodes of acute pancreatitis induced by six intraperitoneal injections of $50 \mu \mathrm{g} / \mathrm{kg}$ body weight cerulein at hourly intervals, per week for 3 consecutive weeks. Mice were infected once with AdT $\beta$-ExR, or with a control adenoviral vector expressing bacterial $\beta$-galactosidase (AdLacZ). Pancreatic fibrosis was evaluated by histology and hydroxyproline content. Activation of pancreatic stellate cells (PSCs) was assessed by immunostaining for $\alpha$-smooth muscle actin. Apoptosis and proliferation of acinar cells were assessed by immunostaining of ssDNA and $\mathrm{Ki}-67$, respectively. Three-week cerulein injection induced pancreatic fibrosis and pancreatic atrophy with proliferation of activated PSCs. In AdT $\beta$-ExR-injected mice, but not AdLacZ-injected mice, pancreatic fibrosis was significantly attenuated. This finding was accompanied by a reduction of activated PSCs. AdT $\beta$-ExR, but not AdLacZ, significantly increased pancreas weight after chronic pancreatic injury. AdT $\beta$-ExR did not change the proportion of proliferating acinar cells, whereas it reduced the number of apoptotic acinar cells. Our results demonstrate that inhibition of TGF- $\beta$ action not only decreases pancreatic fibrosis but also protects the pancreas against chronic injury by preventing acinar cell apoptosis.
\end{abstract}

Laboratory Investigation (2004) 84, 1610-1618, advance online publication, 25 October 2004; doi:10.1038/labinvest.3700191

Keywords: apoptosis; chronic pancreatic injury; pancreatic fibrosis; pancreatic stellate cells; transforming growth factor- $\beta$

Identification of the molecular mechanisms involved in fibrosis of critical organs and the development of effective therapy are both clinically important. Transforming growth factor- $\beta$ (TGF- $\beta$ ) is thought to regulate the production, degradation, and accumulation of extracellular matrix (ECM) proteins, and to play an important role in the fibroproliferative changes that follow tissue injury in many vital organs and tissues, including the heart, lung, kidney, and liver. ${ }^{1-7}$ Chronic pancreatitis is an irreversible progressive disease characterized by

Correspondence: Dr M Otsuki, MD, PhD, Third Department of Internal Medicine, University of Occupational and Environmental Health, Japan, School of Medicine, 1-1 Iseigaoka, Yahatanishi-ku, Kitakyushu 807-8555, Japan.

E-mail: mac-otsk@med.uoeh-u.ac.jp

Received 5 August 2004; revised and accepted 7 September 2004; published online 25 October 2004 destruction of exocrine parenchyma and its replacement with fibrosis. In fact, expression of TGF- $\beta 1$ is enhanced in human chronic pancreatitis. ${ }^{8-10}$ The importance of TGF- $\beta$ signaling in the formation of fibrosis is underlined by experiments in transgenic mice overexpressing TGF- $\beta 1$ in the pancreas. ${ }^{11,12}$ These animals show histological changes that resemble human chronic pancreatitis including destruction of the exocrine pancreas and progressive accumulation of ECM in the pancreas. These findings support the notion that TGF- $\beta$ plays a pivotal role in pancreatic fibrosis. From a clinical point of view, understanding the in vivo effects of inhibition of TGF- $\beta$ action is another approach to lead to the development of effective therapy. A previous study has demonstrated that inhibition of TGF- $\beta 1$ by TGF- $\beta 1$-neutralizing antibody reduces fibrotic responses in cerulein-induced acute pancreatitis. ${ }^{13}$ However, it has long been a question 
whether inhibition of TGF- $\beta$ is effective against persistent pancreatic fibrosis, and whether it exerts a beneficial effect on the pancreas in the process of chronic injury.

To address these questions, we constructed an adenoviral vector expressing the entire extracellular domain of the type II human TGF- $\beta$ receptor fused to the $\mathrm{Fc}$ portion of human IgG (AdT $\beta$-ExR) and performed the present study. We have previously demonstrated that this soluble TGF- $\beta$ receptor suppresses the action of TGF- $\beta$ both in vitro and in vivo. ${ }^{14,15}$ This soluble receptor is secreted from cells infected with AdT $\beta$-ExR into the circulating blood, reaches remote area, binds to TGF- $\beta$, and thereby inhibits its action. ${ }^{14-16}$ The use of AdT $\beta$-ExR can block the action of TGF- $\beta$ in organs where direct gene transfer seems restrained. As an experimental pancreatic fibrosis model, we used mice treated with repeated cerulein injections, ${ }^{17,18}$ an established animal model of chronic pancreatic injury and pancreatic fibrosis with a pathophysiology that closely resembles that of human chronic pancreatitis.

\section{Materials and methods}

\section{Replication-Defective Recombinant Adenoviruses}

A replication-defective E1- and E3- adenoviral vector (AdT $\beta$-ExR) expressing the entire extracellular domain of the type II human TGF- $\beta$ receptor fused to the Fc portion of human IgG, under the control of a CA promoter comprising a cytomegalovirus enhancer and a chicken $\beta$-actin promoter, was prepared as described previously. ${ }^{14,15}$ An adenoviral vector expressing bacterial $\beta$-galactosidase (AdLacZ) was used as a control adenoviral vector. The titer of the virus stock was assessed by a plaque formation assay using 293 cells and expressed in plaque-forming units (PFU). In previous studies, we showed that serum level of this soluble receptor reached a peak value at 5-7 days after the injection and gradually declined thereafter, but that it was still detectable even at 21 days after injection. ${ }^{14-16}$

\section{Animals}

Male BALB/c mice (Kyudo Co., Kumamoto, Japan) weighing $20-22 \mathrm{~g}$ were used. The animals were kept in a $12 \mathrm{~h}$ light/dark cycle with free access to water and a standard mouse chow. The experiment was carried out under the guidelines of animal experiments of University of Occupational and Environmental Health, Japan, School of Medicine.

\section{Experimental Protocol}

Each mouse received an intraperitoneal injection of either AdT $\beta$-ExR $\left(5 \times 10^{8} \mathrm{PFU}\right)$, AdLacZ ( $\left.5 \times 10^{8} \mathrm{PFU}\right)$, or saline. Based on our previous studies using
AdT $\beta$-ExR, we chose this viral dose $\left(5 \times 10^{8} \mathrm{PFU}\right)$ as the optimal dose in this study. We have shown that this dose of $\operatorname{AdT} \beta$-ExR adequately inhibits TGF- $\beta$ action in remote organs without substantial toxicity in mice. ${ }^{15}$ Three days after adenoviral injections, the mice were submitted to repeated acute pancreatitis episodes to induce chronic pancreatic injury and pancreatic fibrosis as described previously. ${ }^{17,18}$ Acute pancreatitis was elicited by hourly (6 times) intraperitoneal injections of $50 \mu \mathrm{g} / \mathrm{kg}$ body weight cerulein (Sigma-Aldrich, Tokyo, Japan), whereas control animals received a comparable amount of saline. Mice were submitted to three episodes of acute pancreatitis per week for 3 weeks. At the end of this period (3 days after final cerulein treatment), venous blood was collected and the mice were killed by administration of a lethal dose of pentobarbital. Pancreatic tissues were harvested, fixed in $4 \%$ paraformaldehyde buffered with $0.01 \mathrm{M}$ sodium phosphate, $\mathrm{pH}$ 7.4 (PBS) overnight at $4^{\circ} \mathrm{C}$, and embedded in paraffin or frozen immediately in liquid nitrogen for extraction of hydroxyproline.

\section{Histological Examination}

Paraffin sections were stained with hematoxylineosin (H\&E) and Azan-Mallory, or subjected to immunohistochemical staining using antibodies against collagen type I (LSL Co., Ltd., Tokyo), fibronectin (Dako Cytomation, Kyoto, Japan) $\alpha$-smooth muscle actin ( $\alpha$-SMA) (Dako Cytomation), the proliferation marker Ki-67 antigen (Dako Cytomation), and single-stranded DNA (ssDNA) (Dako Cytomation), a specific and sensitive marker of apoptosis. ${ }^{19-22}$ Immunohistochemical staining of $\alpha$-SMA was performed as described previously. ${ }^{23} \mathrm{~A}$ DAKO EnVision system (Dako Cytomation) was used for collagen type I, fibronectin, and ssDNA immunostaining. Immunoreactivity of the Ki-67 antigen was visualized by the labeled streptavidinbiotin method (Dako Cytomation).

For quantitative analysis of apoptosis of acinar cells, the number of ssDNA-positive cells was determined under a high-power field $(\times 400$ magnification, 10 random fields per section). Ki-67 labeling index (the portion of acinar cell nuclei that were Ki-67-positive) was expressed as a percentage of all acinar cells in the sections $(\times 400$ magnification, 10 random fields per section). Five mice were analyzed for each group.

\section{Quantitative Analysis of Pancreatic Fibrosis}

A semiquantitative evaluation of fibrosis in the pancreatic specimen was performed using an Axiophot microscope (Carl Zeiss, Eching, Germany) connected to an IBAS image analysis system (Carl Zeiss) as described previously. ${ }^{23}$ Five nonoverlapping fields per Azan-Mallory-stained 
pancreatic specimen $(n=5)$ were randomly selected at $\times 20$ magnification by an investigator who was unaware of the sample identity. The rate of pancreatic fibrosis was indicated as a percentage of total pancreatic specimen.

We also determined collagen contents in pancreatic tissue quantitatively by measuring pancreatic hydroxyproline content as described previously. ${ }^{24}$

\section{Statistical Analysis}

Data are expressed as means \pm s.e.m. Differences between groups were evaluated by one-way
ANOVA. A $P$-value $<0.05$ was considered to be statistically significant.

\section{Results}

\section{Repetitive Cerulein Injections Induce Pancreatic Fibrosis}

Three-times weekly regimen of cerulein, induced acute pancreatitis followed by pancreatic fibrosis similar to that in human chronic pancreatitis. Although collagen deposition increased after 2 weeks of cerulein treatment, ${ }^{17}$ we performed repetitive
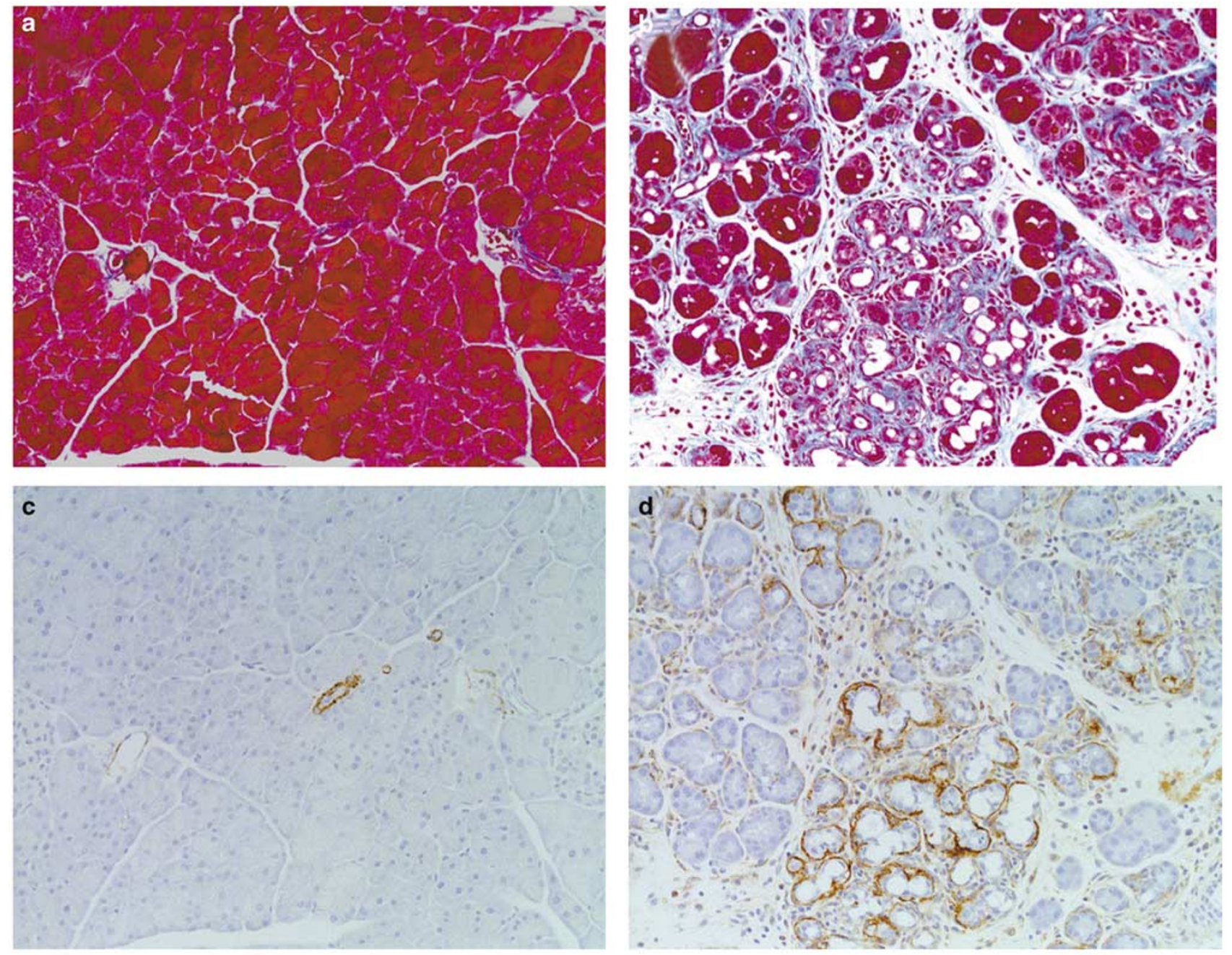

Figure 1 Histological changes in the pancreas after repetitive cerulein injections. Pancreatic tissues of mice treated with cerulein (b and d) or saline as control (a and c) for 3 weeks were stained with Azan (a and b) or subjected to immunostaining for $\alpha$-SMA (c and d). In control pancreas, collagen was seen around the pancreatic ducts and blood vessels (a). Repetitive cerulein treatment for 3 weeks caused intralobular and interlobular fibrosis with inflammatory infiltration and acinar cell atrophy (b). Only a few $\alpha$-SMA-positive cells were present around the blood vessels in control pancreas (c), whereas an increased number of $\alpha$-SMA-positive pancreatic stellate cells (PSCs) were observed in fibrotic area in cerulein-treated mice (d), Original magnification, $\times 200$.

Figure 2 Effects of adenovirus-mediated gene transfer (AdT $\beta$-ExR) on histological changes. Mice were injected once intraperitoneally with either AdLacZ (a, c, e, and $\mathbf{g})$ or $\operatorname{AdT} \beta-\operatorname{ExR}(\mathbf{b}, \mathbf{d}, \mathbf{f}$, and $\mathbf{h})$, or with saline (not shown), and then treated with cerulein for 3 weeks. Pancreatic sections were histologically examined by Azan staining (a and $\mathbf{b}$ ) or by immunostaining with antibodies against $\alpha$-SMA (c and d), collagen type I (e and f), or fibronectin ( $(\mathbf{g}$ and $\mathbf{h}$ ). In mice treated with AdT $\beta$-ExR, $\alpha$-SMA-positive cells, collagen type I, and fibronectin ware clearly reduced compared with those in AdLacZ-treated mice. Original magnification, $\times 200$. 
AdLacZ

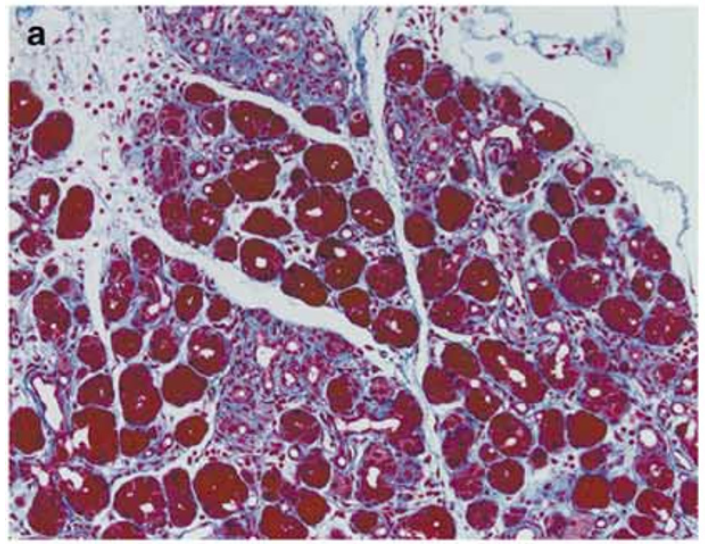

c
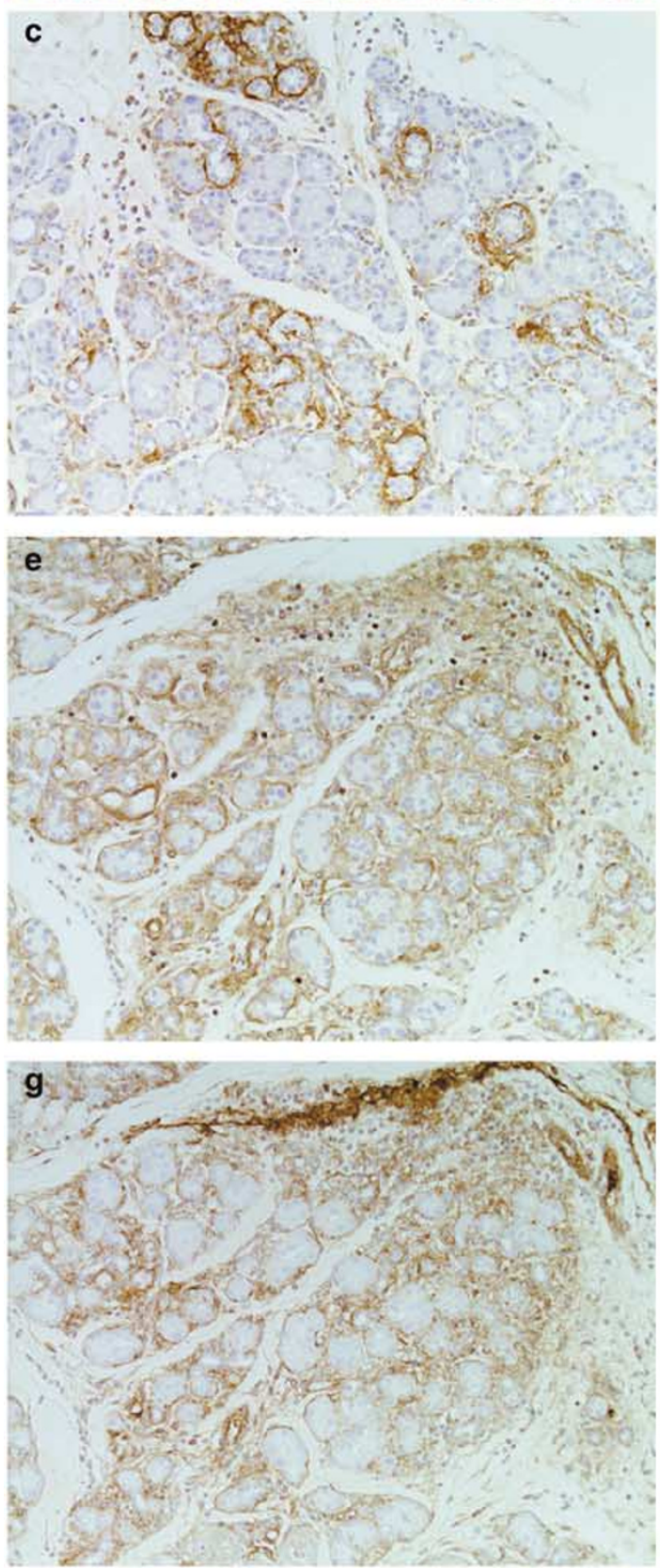

AdT $\beta$-ExR
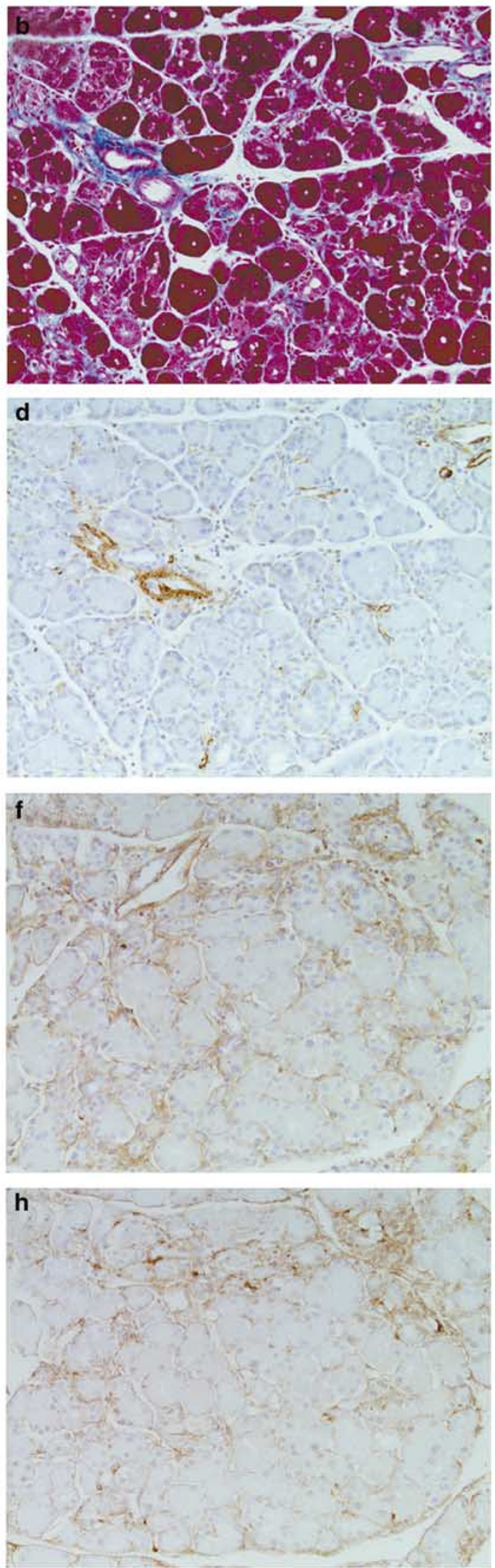
intraperitoneal injections of cerulein for 3 weeks to induce fibrosis in the pancreas. In normal pancreas, collagen was observed around the pancreatic ducts and blood vessels (Figure 1a). Cerulein injections induced massive collagen deposition in periacinar and interlobular areas with inflammatory infiltration and pancreatic atrophy (Figure 1b). In addition, intra-acinar lumina became dilated and some acinar units appeared to redifferentiate into tubular complexes (Figure 1b).

Pancreatic stellate cells (PSCs) are known to mediate fibrogenesis in pancreas. ${ }^{25-30}$ When activated by profibrogenic mediators, PSCs transform into myofibroblast-like cells expressing $\alpha$-SMA. In normal pancreas, $\alpha$-SMA staining was seen mainly in blood vessel walls (Figure 1c). On the other hand, cerulein injections induced the proliferation of $\alpha$-SMA-positive activated PSCs in the fibrotic areas (Figure 1d). These findings indicate that PSCs are responsible for pancreatic fibrosis in ceruleintreated mice and that this model is suitable for investigating fibrosis in the pancreas.

\section{AdT $\beta$-ExR Attenuates Pancreatic Fibrosis}

In AdLacZ-injected mice, intraperitoneal injections of cerulein induced tissue remodeling in the pancreas, with ECM protein deposition mainly in the periacinar and the interlobular areas, as shown by Azan staining (Figure 2a) and immunostainings for collagen type I and fibronectin (Figure 2e and g). The fibrotic area was also stained positively by an antibody against $\alpha$-SMA (Figure 2a and c). These histological changes were not significantly different from those of cerulein-treated mice injected with saline (data not shown). In contrast, AdT $\beta$-ExRinjected mice showed significant reduction of pancreatic fibrosis, as indicated by both Azan staining and immunostaining (Figure $2 \mathrm{~b}, \mathrm{f}$, and $\mathrm{h}$ ). Moreover, AdT $\beta$-ExR reduced the $\alpha$-SMA-positive area (Figure 2d vs $\mathrm{c}$ ).

Semiquantitative analysis of pancreatic fibrosis was performed by image analysis. Image analysis showed that the percentage of fibrotic area of AdT $\beta$ ExR-treated mice was markedly lower than in mice injected with either AdLacZ or saline (Figure 3a). For quantitative comparison, we measured the hydroxyproline content in the pancreas. In cerulein-treated mice injected with either AdLacZ or saline, the amount of hydroxyproline was 5 times higher than that found in control mice (ie, mice not treated with cerulein) (Figure $3 \mathrm{~b}$ ). In contrast, the hydroxyproline content in mice injected once with AdT $\beta$-ExR was significantly decreased (Figure 3b).

\section{Attenuation of Fibrosis by AdT $\beta$-ExR Reduces Loss of Pancreas Weight}

A marked decrease in pancreas wet weight, which reflects pancreatic atrophy after chronic injury,
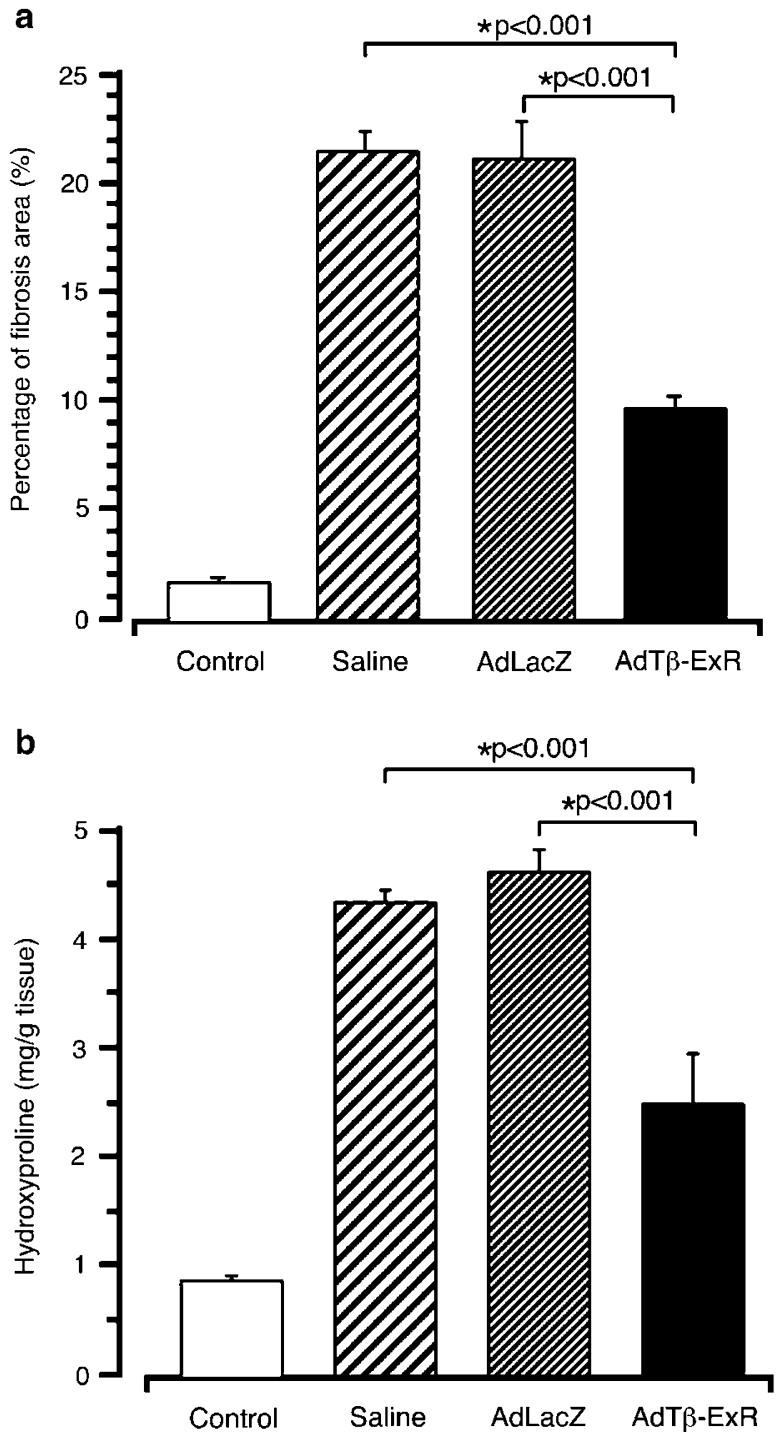

Figure 3 Effects of AdT $\beta$-ExR on fibrosis area and hydroxyproline content in the pancreas. (a) Image analysis of the fibrosis area in the pancreas, which was performed as described in Materials and methods, showed a significant decrease only in the AdT $\beta$-ExRinjected mice. (b) Hydroxyproline content in the pancreas showed a significant decrease only in the $\operatorname{AdT} \beta$-ExR-injected mice. Pancreatic fibrosis was significantly decreased by AdT $\beta$-ExR. Data are mean \pm s.e.m. of 4 or 5 mice/group.

was noted in cerulein-treated mice injected with either AdLacZ or saline, but this decrease was significantly attenuated in mice treated with AdT $\beta$ ExR (Figure 4).

An imbalance between apoptosis and proliferation in acinar cells is thought to be a possible mechanism involved in pancreatic exocrine cell loss of chronic pancreatitis. ${ }^{31}$ We therefore assessed apoptosis and proliferation of acinar cells by immunostaining of ssDNA and Ki-67, respectively. The number of ssDNA-positive cells was increased in exocrine pancreas of cerulein-treated mice 


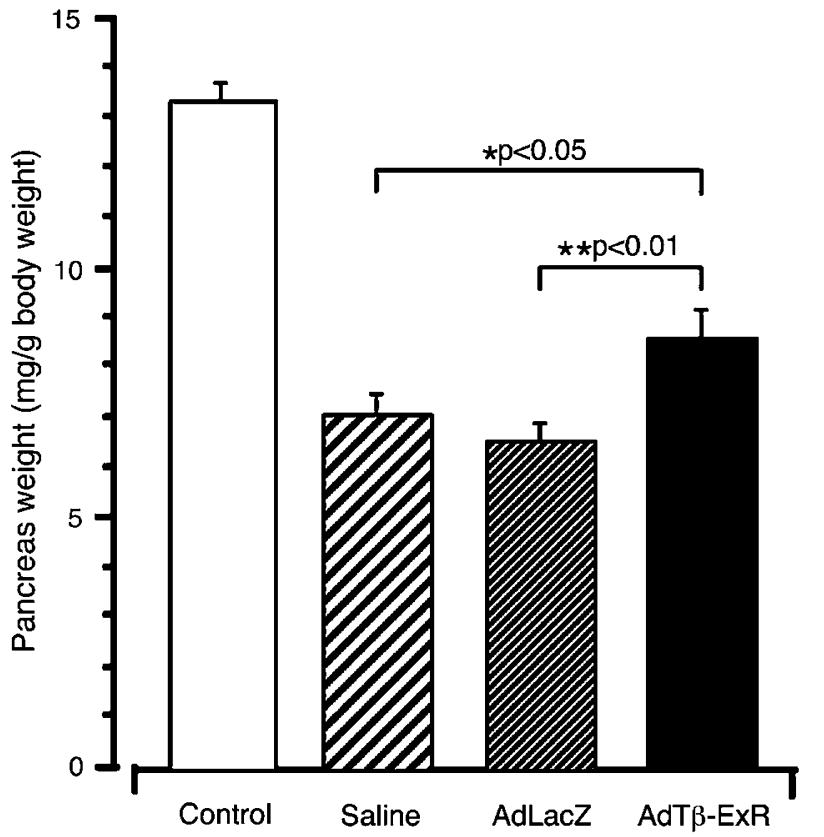

Figure 4 Effect of AdT $\beta$-ExR on pancreas weight. Pancreas weight was determined in control, cerulein-treated, cerulein- and AdLacZ-treated, and cerulein- and AdT $\beta$-ExR-treated mice at the end of the 3-week study period, as described in Materials and methods. Pancreas weight was significantly increased in AdT $\beta$ ExR-injected mice. Data are mean \pm s.e.m. of 5 mice/group.

injected with either AdLacZ or saline, whereas it was significantly decreased in mice treated with AdT $\beta$-ExR (Figure 5a-c).

The Ki-67-positive acinar cells were rarely seen in control mouse pancreas (Figure 6a), whereas they were increased in cerulein- and saline-treated (Figure 6b) or cerulein- and AdLacZ-treated mice (Figure 6c). Treatment with AdT $\beta$-ExR had no influence on the Ki-67 labeling index compared with that with AdLacZ (Figure 6d vs c, and Table 1).

\section{Discussion}

TGF- $\beta$ is a major cytokine in the regulation of the production, degradation, and accumulation of ECM. Overexpression of TGF- $\beta$ for a prolonged period of time after tissue damage induces a fibroproliferative response and deposition of ECM, resulting in fibrosis in vital organs. ${ }^{2-7}$ Many studies have demonstrated the presence of TGF- $\beta 1$ in the form of either protein or message, in the fibrotic tissues of human chronic pancreatitis and animal models. ${ }^{8-10,23,32}$ Van Laethem et $a l^{33}$ demonstrated that repeated injections of recombinant TGF- $\beta$ into mice after recurrent episodes of acute pancreatitis led to pancreatic fibrosis. On the other hand, Menke et $a l^{13}$ have demonstrated that inhibition of TGF- $\beta 1$ by TGF- $\beta 1$-neutralizing antibody causes partial

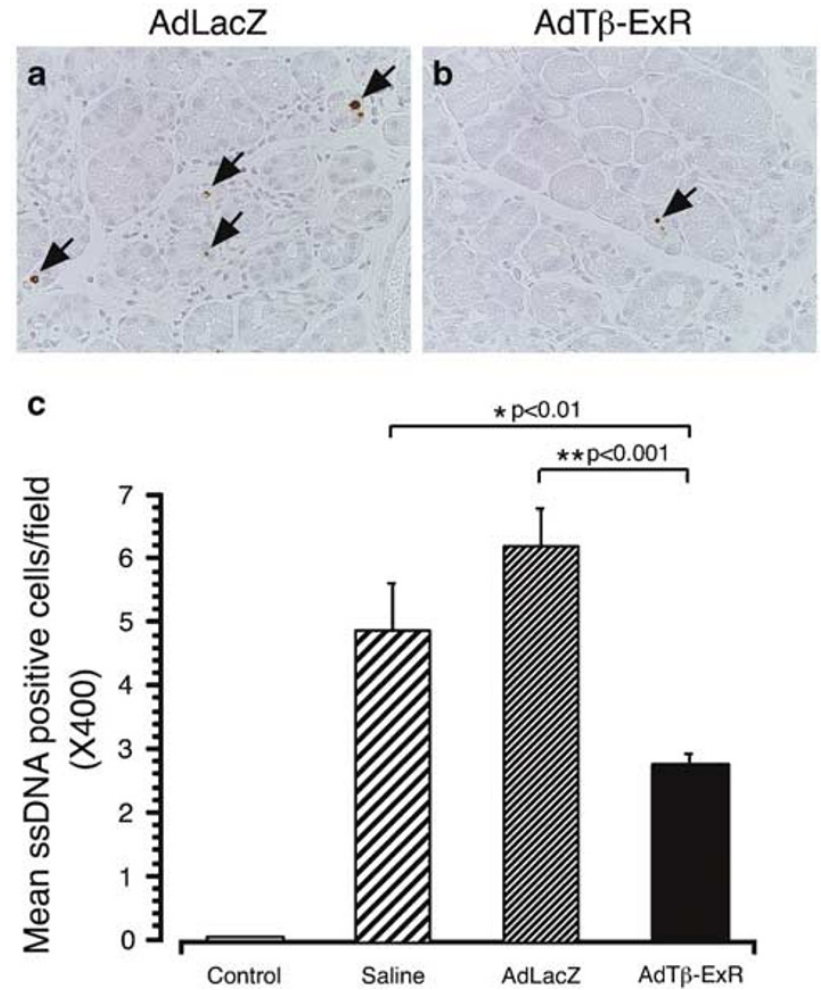

Figure 5 Effect of AdT $\beta$-ExR on apoptosis of acinar cells. A sensitive and specific marker of apoptosis ssDNA-positive cells (arrows) in the AdT $\beta$-ExR-injected mice (b) were reduced compared with those in AdLacZ-injected mice (a). Original magnification, $\times 400$. (c) The numbers of ssDNA-positive cells was determined in control, cerulein-treated, cerulein- and AdLacZ-treated, and cerulein- and AdT $\beta$-ExR-treated mice at the end of the 3-week study period, as described in Materials and methods. The number of apoptotic acinar cells was significantly decreased in the AdT $\beta$-ExR-injected mice. Data are mean \pm s.e.m. of 5 mice/group.

reduction of the accumulation of ECM (collagen type I and III, and fibronectin) during regeneration from the cerulein-induced acute pancreatitis. However, it has not been addressed in a persistent pancreatic fibrosis model whether inhibition of TGF- $\beta$ action is effective in preventing fibrosis in the pancreas, and whether it exerts a beneficial effect on the pancreas in the process of chronic injury. The present study has answered all these questions by adenovirus-mediated expression of a soluble TGF- $\beta$ receptor that can abolish TGF- $\beta$ signaling. ${ }^{14-16}$

It is now recognized that repeated episodes of acute pancreatitis can lead to increasing residual damage to the gland, eventually resulting in chronic pancreatitis (the necrosis-fibrosis sequence). ${ }^{17,34,35}$ Therefore, we chose this chronic pancreatitis model induced by repeated acute pancreatitis in the present study. Although pancreatic fibrosis advanced in both AdLacZ- or saline-treated mice after a total of nine episodes of acute pancreatitis, the progression of fibrosis was greatly impeded in the 

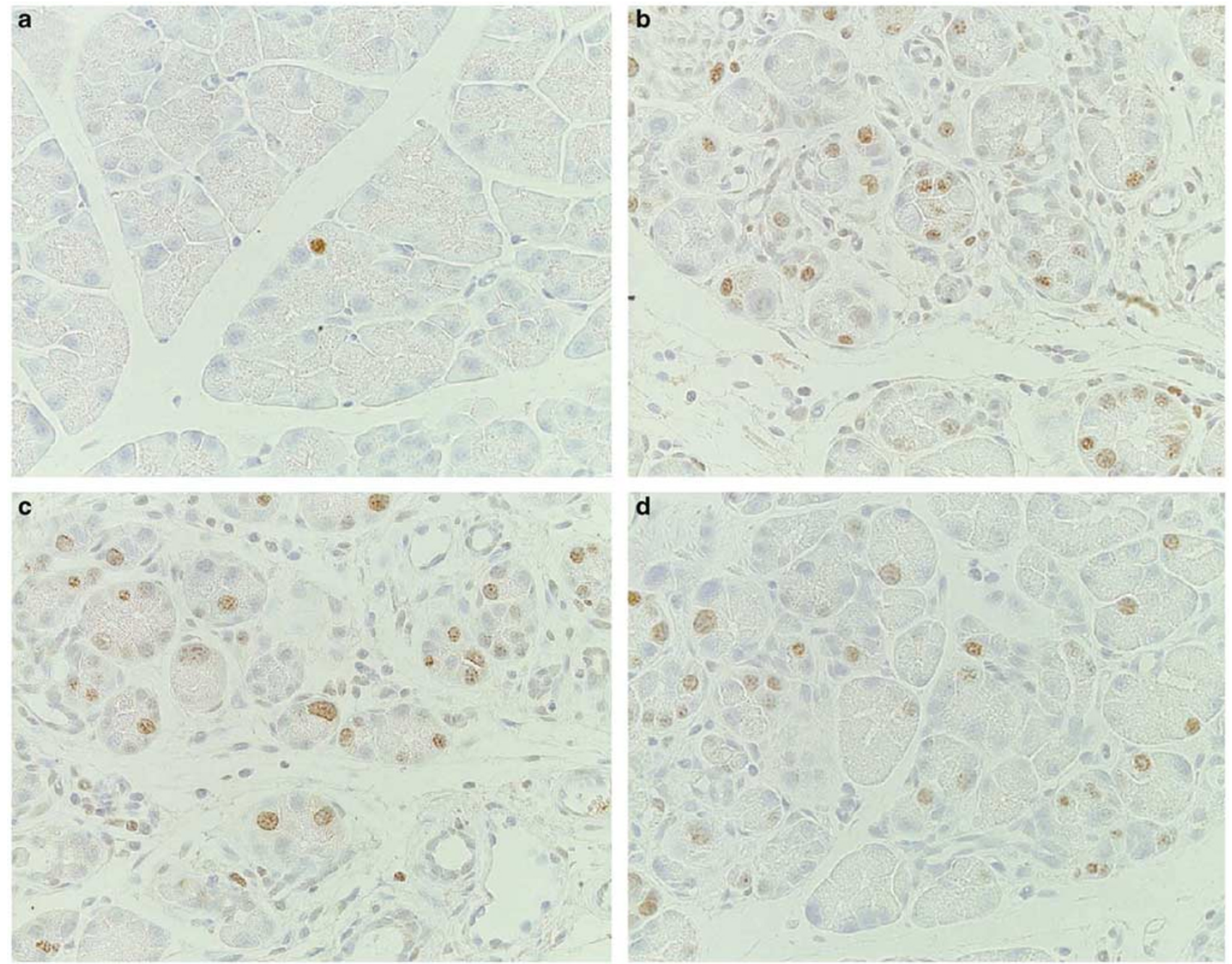

Figure 6 Activity of cellular proliferation in the pancreas of mice treated with cerulein for 3 weeks. Mice were injected once intraperitoneally with either AdLacZ or AdT $\beta$-ExR, or with saline, and then treated with cerulein for 3 weeks. Pancreatic sections were subjected to immunostaining using a Ki-67 antibody, which detects proliferative cells. (a) Ki-67-positive cells were extremely rare in control pancreas. Ki-67-positive cells were increased in the cerulein- and saline-treated (b), the cerulein- and AdLacZ-treated (c), and the cerulein- and AdT $\beta$-ExR-treated (d) mice. Original magnification, $\times 400$.

Table 1 Ki-67 labeling index for acinar cells

\section{Group}

Labeling index (\%)

Cerulein-saline

Cerulein-AdLacZ

Cerulein-AdT $\beta$-ExR

$22.1 \pm 2.8$

$17.6 \pm 1.1$

$20.0 \pm 2.0$

Mice were injected once intraperitoneally with either AdLacZ or AdT $\beta$-ExR, or with saline, and then treated with cerulein for 3 weeks. Pancreatic sections were subjected to Ki-67 staining. Ki-67 labeling index was expressed as a percentage of all acinar cell in the sections ( $\times 400$ magnification, 10 random fields per section). There was no significant difference in Ki-67 labeling index among each group. Data are mean \pm s.e.m. of 5 mice/group.

AdT $\beta$-ExR-treated mice, as assessed by both histology (Figure 2) and quantitation of hydroxyproline contents in the pancreas (Figure 3). Moreover, the immunostaining analysis revealed that attenuation of pancreatic fibrosis by inhibition of TGF- $\beta$ is accompanied by a reduction of activated PSCs. Accumulating evidence indicates that PSCs play a central role in the pathogenesis of pancreatic fibrosis. ${ }^{25-30}$ In response to pancreatic injury or inflammation, PSCs transform into myofibroblastlike phenotype expressing $\alpha$-SMA, proliferate, and synthesize and secrete increased amounts of ECM proteins, particularly collagens and fibronectin. TGF- $\beta$ plays key roles both in the activation of PSCs and in the stimulation of ECM protein synthesis. ${ }^{26,27,29,30}$ Moreover, previous studies strongly support the existence of autocrine and paracrine stimulatory loops of ECM protein synthesis in PSCs via TGF- $\beta .^{36-38}$ Thus, inhibition of TGF- $\beta$ action may block these loops and thereby inhibit PSC activation and ECM protein deposition in the pancreas. However, the inhibitory effect of $\operatorname{AdT} \beta$-ExR on pancreatic fibrosis was less impressive than that 
on liver fibrosis. This finding could be attributable to the difference of organs, the liver and the pancreas. Since the blood flow into the liver is more abundant than that into the pancreas, it is conceivable that the amount of soluble TGF- $\beta$ receptor that reaches the liver after an adenoviral injection may be higher than that in the pancreas. The soluble TGF- $\beta$ receptor in this study is fused to the Fc portion of human IgG as a tag protein. Thus, we can assess the existence of the soluble TGF- $\beta$ receptor in organs by immunohistochemical staining for human IgG (tag protein). Indeed, in our preliminary study, we have revealed that no staining for human IgG was observed in the pancreas of the cerulein- and AdT $\beta$-ExR-treated mice at the end of the study (24 days after an adenoviral injection), whereas a positive staining was observed in the sinusoidal space in the liver of the cerulein- and AdT $\beta$-ExR-treated mice.

Another key finding in this study was that inhibition of TGF- $\beta$ action significantly increased pancreas weight. ECM participates in the process of tissue repair after injury as well as in the development of fibrosis. Thus, one important question arises whether inhibition of ECM protein deposition through blockade of TGF- $\beta$ action has beneficial effects on the pancreas in the process of chronic injury. In the present study, we found that inhibition of TGF- $\beta$ action significantly protected pancreatic acinar cells from apoptosis. Previous studies demonstrated that apoptosis plays a significant role in acinar cell loss in chronic pancreatitis, ${ }^{31}$ and that TGF- $\beta$ induces apoptosis in a broad range of cell types. ${ }^{39-41}$ Thus, inhibition of TGF- $\beta$ action may attenuate pancreatic atrophy, in part by preventing acinar cell apoptosis. Since TGF- $\beta 1$ has been demonstrated to be an inhibitor of pancreatic acinar cell growth in vitro, ${ }^{42}$ it is conceivable that the increased pancreas weight by inhibiting TGF- $\beta$ action might partially result from the enhanced proliferation of acinar cells. However, proliferation of acinar cells assessed by Ki-67 labeling index showed no significant differences between AdT $\beta$ ExR- and AdLacZ-treated mice. These differences can be explained by the differences in the experimental designs (ie, in vivo and in vitro). Under in vivo condition, a variety of factors besides TGF- $\beta$ may regulate acinar cells proliferation in the process of chronic pancreatic injury. In fact, epidermal growth factor (EGF), fibroblast growth factor (FGF), and cholecystokinin (CCK) are known to regulate pancreatic acinar cell growth. ${ }^{42-44}$ Considered together, these results suggest that inhibition of TGF- $\beta$ action provides protection against chronic pancreatic injury by preventing acinar cell apoptosis.

In conclusion, our results demonstrate that inhibition of TGF- $\beta$ action not only decreases pancreatic fibrosis but also protects the pancreas against chronic injury by preventing acinar cells apoptosis. Therefore, this study suggests that inhibition of TGF- $\beta$ may be a potential therapeutical strategy for chronic pancreatitis. However, since elimination of the TGF- $\beta$ signaling for a prolonged period might produce unfavorable consequences such as the inflammation and tissue necrosis as observed in TGF- $\beta 1$ gene-disrupted mice, ${ }^{45}$ we have to investigate carefully these issues in future studies.

\section{Acknowledgements}

We thank Ms Hitomi Kamio and Naoko Kamichi for their excellent technical assistance. This work was supported in part by a Grant-in-Aid from the Ministry of Health, Labour and Welfare (Intractable Diseases of the Pancreas).

\section{References}

1 Massague J. The transforming growth factor- $\beta$ family. Annu Rev Cell Biol 1990;6:597-641.

2 Broekelmann TJ, Limper AH, Colby TV, et al. Transforming growth factor $\beta 1$ is present at sites of extracellular matrix gene expression in human pulmonary fibrosis. Proc Natl Acad Sci USA 1991;88: 6642-6646.

3 Sporn MB, Roberts AB. Transforming growth factor- $\beta$ : recent progress and new challenges. J Cell Biol 1992; 119:1017-1021.

4 Yoshioka K, Takemura T, Murakami K, et al. Transforming growth factor- $\beta$ protein and mRNA in glomeruli in normal and diseased human kidneys. Lab Invest 1993;68:154-163.

5 Friedman SL. The cellular basis of hepatic fibrosis. Mechanisms and treatment strategies. N Engl J Med 1993;328:1828-1835.

6 Border WA, Noble NA. Transforming growth factor $\beta$ in tissue fibrosis. N Engl J Med 1994;331:1286-1292.

$7 \mathrm{Li}$ RK, Li G, Mickle DA, et al. Overexpression of transforming growth factor- $\beta 1$ and insulin-like growth factor-I in patients with idiopathic hypertrophic cardiomyopathy. Circulation 1997;96:874-881.

8 Van Laethem JL, Deviere J, Resibois A, et al. Localization of transforming growth factor $\beta 1$ and its latent binding protein in human chronic pancreatitis. Gastroenterology 1995;108:1873-1881.

9 Satoh K, Shimosegawa T, Hirota M, et al. Expression of transforming growth factor $\beta 1$ (TGF $\beta 1$ ) and its receptors in pancreatic duct cell carcinoma and in chronic pancreatitis. Pancreas 1998;16:468-474.

10 Ishihara T, Hayasaka A, Yamaguchi T, et al. Immunohistochemical study of transforming growth factor- $\beta 1$, matrix metalloproteinase-2, 9, tissue inhibitors of metalloproteinase-1, 2, and basement membrane components at pancreatic ducts in chronic pancreatitis. Pancreas 1998;17:412-418.

11 Lee MS, Gu D, Feng L, et al. Accumulation of extracellular matrix and developmental dysregulation in the pancreas by transgenic production of transforming growth factor- $\beta 1$. Am J Pathol 1995;147:42-52.

12 Sanvito F, Nichols A, Herrera PL, et al. TGF- $\beta 1$ overexpression in murine pancreas induces chronic pancreatitis and, together with $\mathrm{TNF}-\alpha$, triggers insulindependent diabetes. Biochem Biophys Res Commun 1995;217:1279-1286. 
13 Menke A, Yamaguchi H, Gress TM, et al. Extracellular matrix is reduced by inhibition of transforming growth factor $\beta 1$ in pancreatitis in the rat. Gastroenterology 1997;113:295-303.

14 Ueno H, Sakamoto T, Nakamura T, et al. A soluble transforming growth factor $\beta$ receptor expressed in muscle prevents liver fibrogenesis and dysfunction in rats. Hum Gene Ther 2000;11:33-42.

15 Sakamoto T, Ueno H, Sonoda K, et al. Blockade of TGF$\beta$ by in vivo gene transfer of a soluble TGF- $\beta$ type II receptor in the muscle inhibits corneal opacification, edema and angiogenesis. Gene Therapy 2000;7: 1915-1924.

16 Zhou A, Ueno $H$, Shimomura $M$, et al. Blockade of TGF- $\beta$ action ameliorates renal dysfunction and histologic progression in anti-GBM nephritis. Kidney Int 2003;64:92-101.

17 Neuschwander-Tetri BA, Bridle KR, Wells LD, et al. Repetitive acute pancreatic injury in the mouse induces procollagen $\alpha 1(\mathrm{I})$ expression colocalized to pancreatic stellate cells. Lab Invest 2000;80:143-150.

18 Nagashio Y, Asaumi H, Watanabe S, et al. Angiotensin II type 1 receptor interaction is an important regulator for the development of pancreatic fibrosis in mice. Am J Physiol Gastrointest Liver Physiol 2004;287: G170-G177.

19 Watanabe I, Toyoda M, Okuda J, et al. Detection of apoptotic cells in human colorectal cancer by two different in situ methods: antibody against singlestranded DNA and terminal deoxynucleotidyl transferase-mediated dUTP-biotin nick end-labeling (TUNEL) methods. Jpn J Cancer Res 1999;90:188-193.

20 Korkolopoulou PA, Konstantinidou AE, Patsouris ES, et al. Detection of apoptotic cells in archival tissue from diffuse astrocytomas using a monoclonal antibody to single-stranded DNA. J Pathol 2001;193: 377-382.

$21 \mathrm{Su}$ SB, Motoo Y, Iovanna JL, et al. Overexpression of p8 is inversely correlated with apoptosis in pancreatic cancer. Clin Cancer Res 2001;7:1320-1324.

22 Tashiro M, Nakamura H, Taguchi M, et al. Expression of survivin after acute necrohemorrhagic pancreatitis in rats. Pancreas 2003;26:160-165.

23 Yoshikawa H, Kihara Y, Taguchi M, et al. Role of TGF$\beta 1$ in the development of pancreatic fibrosis in Otsuka Long-Evans Tokushima Fatty rats. Am J Physiol Gastrointest Liver Physiol 2002;282:G549-G558.

24 Woessner JFJ. The determination of hydroxyproline in tissue and protein samples containing small amounts of the amino acid. Arch Biochem Biophys 1961; 93:440-447.

25 Apte MV, Haber PS, Applegate TL, et al. Periacinar stellate shaped cells in rat pancreas: identification, isolation, and culture. Gut 1998;43:128-133.

26 Bachem MG, Schneider E, Gross H, et al. Identification, culture, and characterization of pancreatic stellate cells in rats and humans. Gastroenterology 1998; 115:421-432.

27 Apte MV, Haber PS, Darby SJ, et al. Pancreatic stellate cells are activated by proinflammatory cytokines: implications for pancreatic fibrogenesis. Gut 1999;44: 534-541.

28 Haber PS, Keogh GW, Apte MV, et al. Activation of pancreatic stellate cells in human and experimental pancreatic fibrosis. Am J Pathol 1999;155:1087-1095.

29 Schneider E, Schmid-Kotsas A, Zhao J, et al. Identification of mediators stimulating proliferation and matrix synthesis of rat pancreatic stellate cells. Am J Physiol Cell Physiol 2001;281:C532-C543.

30 Mews P, Phillips P, Fahmy R, et al. Pancreatic stellate cells respond to inflammatory cytokines: potential role in chronic pancreatitis. Gut 2002;50:535-541.

31 Bateman AC, Turner SM, Thomas KS, et al. Apoptosis and proliferation of acinar and islet cells in chronic pancreatitis: evidence for differential cell loss mediating preservation of islet function. Gut 2002;50: 542-548.

32 Sparmann G, Merkord J, Jaschke A, et al. Pancreatic fibrosis in experimental pancreatitis induced by dibutyltin dichloride. Gastroenterology 1997;112: 1664-1672.

33 Van Laethem JL, Robberecht P, Resibois A, et al. Transforming growth factor $\beta$ promotes development of fibrosis after repeated courses of acute pancreatitis in mice. Gastroenterology 1996;110:576-582.

34 Kloppel G, Maillet B. The morphological basis for the evolution of acute pancreatitis into chronic pancreatitis. Virchows Arch A 1992;420:1-4.

35 Ammann RW, Muellhaupt B. Progression of alcoholic acute to chronic pancreatitis. Gut 1994;35:552-556.

36 Luttenberger T, Schmid-Kotsas A, Menke A, et al. Platelet-derived growth factors stimulate proliferation and extracellular matrix synthesis of pancreatic stellate cells: implications in pathogenesis of pancreas fibrosis. Lab Invest 2000;80:47-55.

37 Schmid-Kotsas A, Gross HJ, Menke A, et al. Lipopolysaccharide-activated macrophages stimulate the synthesis of collagen type I and c-fibronectin in cultured pancreatic stellate cells. Am J Pathol 1999; 155:1749-1758.

38 Shek FW, Benyon RC, Walker FM, et al. Expression of transforming growth factor- $\beta 1$ by pancreatic stellate cells and its implications for matrix secretion and turnover in chronic pancreatitis. Am J Pathol 2002; 160:1787-1798.

39 Rotello RJ, Lieberman RC, Purchio AF, et al. Coordinated regulation of apoptosis and cell proliferation by transforming growth factor $\beta 1$ in cultured uterine epithelial cells. Proc Natl Acad Sci USA 1991;88: 3412-3415.

40 Oberhammer FA, Pavelka M, Sharma S, et al. Induction of apoptosis in cultured hepatocytes and in regressing liver by transforming growth factor $\beta 1$. Proc Natl Acad Sci USA 1992;89:5408-5412.

41 Sanvito F, Herrera PL, Huarte J, et al. TGF- $\beta 1$ influences the relative development of the exocrine and endocrine pancreas in vitro. Development 1994; 120:3451-3462.

42 Logsdon CD, Keyes L, Beauchamp RD. Transforming growth factor- $\beta$ (TGF- $\beta 1$ ) inhibits pancreatic acinar cell growth. Am J Physiol Gastrointest Liver Physiol 1992; 262:G364-G368.

43 Simeone DM, Zhang L, Graziano K, et al. Smad4 mediates activation of mitogen-activated protein kinases by TGF- $\beta$ in pancreatic acinar cells. Am J Physiol Cell Physiol 2001;281:C311-C319.

44 Logsdon CD. Stimulation of pancreatic acinar cell growth by CCK, epidermal growth factor, and insulin in vitro. Am J Physiol Gastrointest Liver Physiol 1986; 251:G487-G494.

45 Shull MM, Ormsby I, Kier AB, et al. Targeted disruption of the mouse transforming growth factor$\beta 1$ gene results in multifocal inflammatory disease. Nature 1992;359:693-699. 